flora bacteriana de la mucosa oral. Presentan baja virulencia aunque clínicamente pueden relacionarse con bacteriemias transitorias tras intervenciones dentarias, siendo el principal agente causante de la endocarditis bacteriana subaguda (1)

El desarrollo de complicaciones en relación al uso de catéteres intravenosos ha sido objeto de muchos trabajos, demostrando incluso algún estudio que tras 6-8 semanas de la inserción de un catéter central el $12,5 \%$ de los pacientes presentan trombos en la punta del mismo $(2,3)$. Entre los mecanismos habituales de formación del trombo destacan la localización del catéter en una zona de relativo estancamiento del flujo sanguíneo o la irritación mecánica sobre la pared libre auricular (2). Se ha visto que la situación del catéter a nivel auricular se asocia en mayor medida con el desarrollo de trombos, frente a la disposición del mismo a nivel de la vena cava superior o la unión cavo-auricular (3).

El diagnóstico de endocarditis deberá ser considerado tanto en aquellos procesos febriles sin foco como en los que debutan con múltiples abscesos sépticos periféricos, sobre todo como si en este caso son portadores de un catéter central. Deberá realizarse mediante un ecocardiograma, prefiriéndose el transesofágico (TEE) por ser mas sensible ( $\mathrm{S}>90 \%$ ) que el transtorácico (TTE), con una sensibilidad del 30-40\% (4). Es además necesaria la realización de un TC para descartar embolismos sépticos periféricos $(2,4,5)$.

El tratamiento consistirá en la terapia antimicrobiana según protocolo o antiobiograma (teniendo en cuenta que la resistencia a la penicilina es común en el grupo viridans) (1) seguida de la extracción del catéter, si bien en nuestro caso dado el tamaño de la vegetación séptica es necesaria la extirpación quirúrgica de la misma para evitar los embolismos sépticos (5).

A. Touceda Bravo, A. M. Cabarcos Ortiz de Barrón, E. González Babarro, E. Fernández Rodríguez, J. A. Torre Carballada ${ }^{1}$, J. Rubio Álvarez ${ }^{2}$

${ }^{1}$ Servicio de Medicina Interna. ${ }^{2}$ Servicio de Cirugía Cardiaca. Hospital Clínico. Santiago de Compostela. A Coruña

1. Westling K, Ljungman P, Thalme A, Julander I. Streptococcus viridans septicaemia: a comparison study in patients admitted to the departments of infectious diseases and haematology in a university hospital. Scand J Infect Dis 2002; 34: 316-9.

2. Ghani MK, Boccalandro F, Denotas AE, Barasch H. Right atrial thrombus formation associated with central venous catheters utilization in hemodiálisis patients. Intensive Care Med 2002; 29: 1829-32.

3. Gilon D, Schechter D, Rein AJ, Gimmon Z, Or R, Rozenman Y, Slavin Set al. Right atrial trombi are related to indwelling central venous catheter position: insights into time course and possible mechanism of formation. Am Heart J 1998; 135: 457-62.

4. Gosbell IB. Diagnosis and management of catheter-related bloodstream infections due to Staphylococcus aureus. Intern Med J 2005; 35: S45-S62.

5. Yamashita S, Noma K, Kuwata G, Miyoshi K, Honaga K.Infective endocarditis at the tricuspid valve following central venous catheterization. J Anesth 2005; 19: 84-7.

\section{Afectación bilateral del tendón de Aquiles por tratamiento con levofloxacino}

\section{Sr. Director:}

El tratamiento antibiótico con fluoroquinolonas puede conllevar diversos tipos de afectación tendinosa como efecto adverso, siendo menos frecuente la rotura bilateral espontánea del tendón de Aquiles. Esto ha sido bien documentado con las antiguas quinolonas aunque cada vez están siendo descritos más casos con las nuevas quinolonas de tercera generación (1-5).

Se han descrito situaciones clínicas asociadas a un mayor riesgo de padecer este tipo de efectos secundarios como son la terapia crónica con esteroides, insuficiencia renal crónica, artritis reumatoide e hiperlipidemia (1).

Presentamos el caso de un paciente que sufre una rotura espontánea bilateral del tendón de Aquiles después de haber recibido tratamiento con levofloxacino por una infección del tracto respiaratorio y en el que los síntomas comenzaron dos semanas después de haber finalizado el tratamiento.

Paciente varón, de 74 años con antecedentes de enfermedad pulmonar obstructiva crónica, fibrilación auricular, patología prostática y varices en miembros inferiores, intervenido de aneurismectomía aórtica e ilíaca con injerto aorto-bifemoral, que ingresa por un cuadro progresivo de siete días de evolución de deterioro del estado general y cefalea.

Analíticamente destaca anemia macrocítica $(\mathrm{Hb} 7,7 \mathrm{mg} / \mathrm{dl}$, VCM 106) y VSG de $140 \mathrm{~mm}$, sin otros datos analíticos alterados. Ante la sospecha de un cuadro de arteritis de la temporal y en espera de biopsia se inicia tratamiento empírico con corticoides a altas dosis (60 mg/día), con resolución del cuadro que motivó el ingreso.

Durante su estancia hospitalaria sufre un proceso de infección respiratoria de origen nosocomial, por lo que se inicia tratamiento empírico con levofloxacino a una dosis de $500 \mathrm{mg}$ al día, vía intravenosa, durante diez días con mejoría clínica importante.

A las dos semanas de haber finalizado el tratamiento antibiótico, el paciente refiere dolor e impotencia funcional en ambos tobillos, así como dolor en la primera articulación metatarsofalángica del primer dedo del pie. Ante la presencia de un cuadro agudo de artritis gotosa se inicia tratamiento con colchicina y antiinflamatorios. El dolor en ambos tobillos persiste así como dificultad para la flexión dorsal del primer dedo de ambos pies. A la exploración, el paciente presenta a la inspección de ambos talones aumento de volumen y equímosis, de consistencia blanda a la palpación, presentando reflejo de Thompson positivo de forma bilateral. Se realiza ecografía de ambos talones, que objetiva rotura completa en zona medial distal del tendón de Aquiles izquierdo y desestructuración y adelgazamiento que sugiere rotura sin discontinuidad completa en el derecho.

Se realiza tratamiento conservador con yeso inguinopédico durante dos semanas y seguimiento ambulatorio, con posterior recuperación completa.

La afectación tendinosa es un efecto adverso poco frecuente secundaria al tratamiento con todas las quinolonas de uso clínico, que se ha descrito con una incidencia de 15-20/100.000 pacientes (6) aunque existen estudios que indican que esta frecuencia es mayor (7). La localización más frecuente es el Tendón de Aquiles, como en nuestro caso, aunque se han descrito afectación de otras regiones.

En la mayoría de los casos descritos, a pesar de que la fisiopatología no es del todo bien conocida, el efecto se producía en las primeras horas de toma del fármaco, aunque se han descrito casos en que este efecto aparecía hasta diez días después de haber iniciado el tratamiento (1). El caso que presentamos inició los síntomas después de dos semanas de haber finalizado el tratamiento.

Ha sido ampliamente documentada la asociación entre la terapia con esteroides de forma crónica y el desarrollo de la tendinopatía. Se ha evidenciado que los pacientes mayores de 60 años y en tratamiento crónico con esteroides, presentaban un riesgo 6veces mayor de sufrir este efecto adverso al estar en tratamiento con quinolonas. Los pacientes que no están a tratamiento crónico con esteroides presentaban un riesgo 2 veces mayor que la población general de sufrir dicho evento. $(7,8)$. El caso que presentamos estaba a tratamiento con corticoides desde el día del ingreso, por lo que no debemos limitar nuestras sospechas a los pacientes en tratamiento crónico. 
Aunque se han ensayado algunos tratamientos como la colchicina, no se ha demostrado un efecto beneficioso en el cuadro clínico de estos pacientes. En nuestro caso se inició tratamiento con colchicina debido a la aparición coincidente de artritis gotosa, sin mejoría clínica. El único tratamiento que ha demostrado su eficacia en cuadros incipientes es el cese de la administración de la quinolona. Una vez la rotura es completa, la única opción terapéutica es la quirúrgica.

Las fluoroquinolonas son un grupo de antimicrobianos que, por su amplio espectro antibacteriano y sus propiedades farmacocinéticas son cada vez más usados en la práctica clínica diaria, lo que conlleva que veamos con mayor frecuencia sus efectos adversos y que deban ser tenidos en cuenta.

\section{E. Fernández Rodríguez ${ }^{1}$, M. Páramo de Vega, A. Cabarcos, A. Touceda ${ }^{2}$, B. Cigarrán, J. A. Torre}

Servicio de Medicina Interna. ${ }^{\text {ISS }}$ ervicio de Endocrinología. ${ }^{2}$ Medicina de Familia. Complejo Hospitalario Universitario. Santiago de Compostela. A Coruña
1. Kowatari K, Nakashima K, Ono A, Yoshihara M, Amano M, Toh S. Levofloxacin induced bilateral Achilles tendon rupture: A case report and review of the literature. J Orthop Sci 2004; 9: 186-90

2. Lado Lado FL, Rodríguez Moreno C, Velasco González M, Durán Parrondo C, Moar. Rotura parical bilateral aquílea asociada a levofloxacino. An Med Interna (Madrid) 2005; 22: 28-30.

3. Tomás ME, Pérez Carreras M, Morillasa JD. Rupture of the Achilles tendon secondary to levofloxacin. Gastroenterol Hepatol 2003; 26: 534

4. De la Red G, Mejia JC, Cervera R, Llado A, Mensa J, Font J. Bilateral Achilles tendonitis with spontaneous rupture induced levofloxacin in a patient with systemic sclerosis. Clin Rheumatol 2003; 22: 367-8.

5. Burkhardt O, Kohnlein T, Pap T, Welte T. Recurrent tendinitis after treatment with two different fluoroquinolones. Scand J Infect Dis 2004; 36: 315-6.

6. Rodríguez Vera FJ, Pereira Vega A, Pujol de la Llave E. Tendinopatía por quinolonas: tratamiento y efecto de clase en dos nuevos casos. Rev Clin Esp 2004; 204: 35-6.

7. Van der Linden PD, Sturkenboom MC, Herings RM, Leufkens HM Stricker BH. Fluoroquinolones and risk of Achilles tendon disorders: case-control study. BMJ 2002; 324: 1306-7.

8. Aros C, Flores C, Mezzano S. Achilles tendinitis associated to levofloxacin: report of 4 cases. Rev Med Chil 2002; 130: 1277-81. 